\title{
INFLUENCE OF RECYCLED AGGREGATE QUALITY ON THE MECHANICAL PROPERTIES OF CONCRETE
}

The use of recycled construction and demolition waste - especially recycled concrete - as an aggregate for new concrete mixes, leads to saving of natural resources and helps to reduce the pressure on landfilling sites. Mostly the quality of recycled concrete is lower compared to standard concrete prepared with the same mix design. The reason for the drop in quality is mainly related to the quality of the recycled aggregate. The high water absorption of recycled aggregate has a negative impact of concrete mix workability and influences the water-cement ratio. This paper presents the effect of recycled aggregate quality on the physical and mechanical properties of concrete. Series of concrete with various replacement ratios of natural aggregate by recycled aggregate were prepared for this study. The obtained results confirm the potential use of developed recycling concrete made with local recycled aggregate in some applications in building construction. This can lead to environmental savings, especially reduction of primary resources use, embodied energy and embodied emissions.

Keywords: Recycled aggregate, recycled concrete, construction and demolition waste, environmental savings.

\section{Introduction}

World concrete production has been twelve times increased in the second half of the last century [1]. Nowadays, concrete is after water the second most used material in the world and the production of concrete totally depends on the natural resources. The rapid development in the construction industries leads to the replacement of old existing buildings with new buildings. Consequently, the amount of demolished concrete structures is very high and is gradually increasing. This creates needs and potential for replacement of natural aggregate by recycled aggregated in the new concrete.

Making use of recycled aggregates helps to reduce primary raw materials depletion, pressure on landfilling sites and amount of construction and demolition waste, which reaches up to $31 \%$ of all waste in the European Union [2]. After World War II, recycled demolition rubble was used instead of natural aggregate to rebuild roads and houses because there were a lot of demolished buildings in Europe, mainly in Germany [3]. Using of recycled aggregate for the purpose of primary materials savings started in 1980' mainly in countries without natural resources of aggregate. So, the research focused on the use of recycled aggregate (RA) derived from construction and demolition waste (CDW), in recycled concrete started [4].

Lower quality of recycled aggregates compared to natural aggregates negatively influences the mechanical properties of recycled concrete [5]. Four types of RA are defined according to the European Standard EN 206-1 [6] in relationship to their composition. Recycled concrete aggregate mainly from crushed concrete (Type I according to EN 206-1) is often used in production of concrete [7]. RA Type I can also include small amounts (up to $10 \%$ in total) of other materials, such as crushed bricks, plasters, ceramic and asphalt particles. Content of these particles depends on a recycling process and origin of waste material [7]. All listed aspects lead to poorer performing properties of RA thaen natural aggregate. On the other hand, it was found that inferior values are not connected with quality of original concrete [8]. Maximum replacement ratio, the percentage of substitution of natural aggregate by RA, was specified by the German Committee for Structural concrete (DAfStb) in 1998 in Germany. Allowed values are based on a 4-years long national research and are published as a supplementary document to DIN 4226-100 [9].

One of the poor properties of RA is the high water absorption capacity [10, 11 and 12], as a result of the attached mortar content and, consequently, higher porosity of aggregate [13 and 14]. Fine fractions of RA contain more cement mortar and impurities such as clay than coarse fractions, which leads to higher absorption and inappropriateness to use it for structural concretes [7, 15 and 16]. High water absorption affects watercement ratio [4 and 17], workability of concrete mix [13] and physical properties such as water absorption and carbonation [7].

\footnotetext{
* ${ }^{1}$ Tereza Pavlu, ${ }^{2}$ Luc Boehme, ${ }^{1}$ Petr Hajek

${ }^{1}$ Department of Building Structures, Faculty of Civil Engineering, Czech Technical University in Prague, Czech Republic

${ }^{2}$ Technology Cluster Construction, Faculty of Engineering Technology, KU Leuven, Oostende, Belgium

E-mail: tereza.pavlu@fsv.cvut.cz
} 
The other physical and mechanical properties of aggregate, which are negatively influenced by presence of adhered mortar, are density [8], resistance to degradation and wear [18].

Workability of fresh concrete, which is affected by water absorption capacity and porosity of used aggregate, has impact properties of fresh and hardened concrete such as density, air content and strength [9]. There are certain ways to get better workability of concrete mix either pre-saturating recycled aggregate before adding it to mix [19] or added water-reducing admixtures [4 and 20]. Compressive strength of RA depends on replacement rate, quality and composition of RA [21] and also on effective water-cement ratio [22]. So, the paper presents and discusses experimental results of mechanical properties of recycled concrete. Tested concretes contained different ratios of recycled content and different types of recycled aggregate. All samples were tested under uniaxial compressive stress.

\section{Materials and methodology}

\subsection{Materials}

Natural aggregates were extracted from stone quarry in the Czech Republic. Both samples of coarse recycled aggregate came from the same CDW treatment plant in the Czech Republic. Laboratory crushed recycled aggregates from concrete cubes were prepared from several concrete mixes whose properties are described in Table 1.

- Sand (S): grain size 0/4 mm

- Natural aggregate (NA): grain size $4 / 8 \mathrm{~mm}$ and $8 / 16 \mathrm{~mm}$, from crushed mix gravel

- Laboratory prepared recycled aggregate (LRA): grain size $0 / 16 \mathrm{~mm}$, from crushing concrete approximately 100 days old, the composition of mixtures is described in Table 1.

- Recycled aggregate from recycling plant (RA1): grain size $4 / 16 \mathrm{~mm}$, containing $76 \%$ crushed concrete, $18 \%$ of masonry, $5 \%$ of asphalt and other materials, were defined as type 4 . mixed recycled concrete according to standard [6].
- Recycled aggregate from recycling plant (RA2): grain size $4 / 16 \mathrm{~mm}$, containing $96 \%$ of crushed concrete, $1 \%$ of masonry, $1 \%$ of asphalt and other, were defined as type 1 mixed recycled concrete according to standard [6].

One natural aggregate, two samples (RA1 \& RA2) of coarse recycled aggregate from recycling plant and three samples (LRA1, LRA2 \& LRA3) of laboratory prepared recycled aggregate were tested and used as aggregates for a new concrete.

Figure 1 shows the images and compositions of RA. The geometrical and physical properties of all types of aggregates were determined and shown in Table 2.

Mechanical properties and composition of original concrete cubes used for preparing laboratory made recycled aggregate Table 1

\begin{tabular}{|llll|}
\hline \multirow{2}{*}{ Class of concrete } & C 30/37 & C60/75 & C20/25 \\
\cline { 2 - 3 } & (LRA 1) & (LRA 2) & (LRA 3) \\
\hline Composition of mixes $\left(\mathrm{kg} / \mathrm{m}^{3}\right)$ & & & \\
Natural sand 0/4 mm & 774 & 820 & 935 \\
Natural aggregate $4 / 8 \mathrm{~mm}$ & 345 & 350 & 400 \\
Natural aggregate $8 / 16 \mathrm{~mm}$ & 641 & 750 & 855 \\
Cement & 345 & 475 & 275 \\
Water & 181 & 180 & 165 \\
Water-reducing admixtures & - & 4.8 & - \\
Water-cement ratio & 0.52 & 0.38 & 0.60 \\
\hline Compressive strength $(\mathrm{MPa})$ & 42.3 & 70.8 & 28.5 \\
Tensile strength $(\mathrm{MPa})$ & 4.6 & 6.8 & 4.2 \\
Modulus of elasticity $(\mathrm{GPa})$ & 27.2 & 36.2 & 29.7 \\
$\begin{array}{l}\text { Density of hardened } \\
\text { concrete }\left(\mathrm{kg} / \mathrm{m}^{3}\right)\end{array}$ & 2285 & 2580 & 2630 \\
$\begin{array}{l}\text { Density of aggregate }\left(\mathrm{kg} / \mathrm{m}^{3}\right) \\
\text { Water absorption of }\end{array}$ & 2446 & 2439 & 2439 \\
aggregate $(\%)$ & 3.86 & 3.71 & 3.47 \\
\hline
\end{tabular}

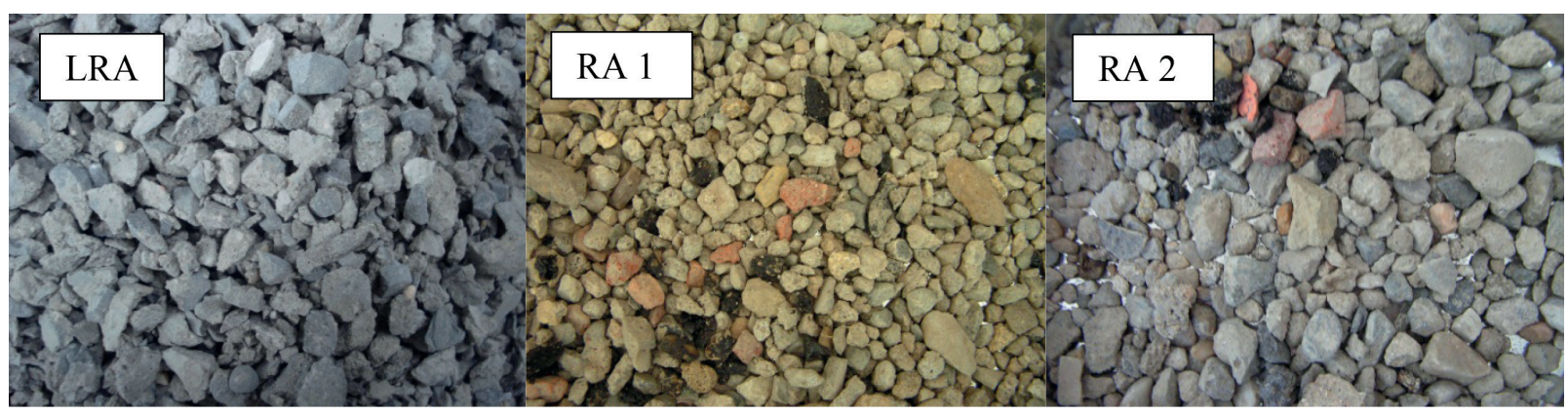

Fig. 1 Used recycled aggregates 
Physical properties of all used types of aggregate

Table 2

\begin{tabular}{|llll|}
\hline Type of aggregate & Grading & $\begin{array}{l}\text { Oven-dry } \\
\text { particle } \\
\text { density }\end{array}$ & $\begin{array}{l}\text { Water } \\
\text { absorption }\end{array}$ \\
\cline { 2 - 4 } & $\mathbf{( m m )}$ & $\mathbf{( k g / \mathbf { m } ^ { 3 } )}$ & $\mathbf{( \% )}$ \\
\hline Natural sand (S) 0/4 mm & $0-4$ & 2603 & 1.30 \\
Natural aggregate (NA) & $4-8$ & 2675 & 1.12 \\
4/16 mm & $8-16$ & 2654 & 0.79 \\
Laboratory recycled & $4-8$ & 2284 & 7.51 \\
aggregate (LRA) 4/16 mm & $8-16$ & 2408 & 3.68 \\
Recycled aggregate (RA1) & $4-8$ & 2181 & 10.38 \\
& $8-16$ & 2254 & 7.53 \\
Recycled aggregate (RA2) & $4-8$ & 2147 & 9.18 \\
& $8-16$ & 2220 & 7.01 \\
\hline
\end{tabular}

\subsection{Concrete mix proportion}

The two different ways were adopted in concrete mixtures preparations. For each test series was designed own reference mixture with only natural aggregate for relevant comparison within each test series. The first way was adopted for laboratory prepared aggregate. The amount of water was modified according to water absorption capacity of the RA. In these mixtures fractions $0-16 \mathrm{~mm}$ of laboratory prepared recycled aggregate (LRA) were used. The fine fraction was included in the recycled concrete mixture because of high content of cement. Prepared mixtures are listed in Table 3. The second way was adopted for RA from the recycling plant. The amounts of water for these mixtures were calculated according to water absorption capacity of each aggregate to keep the effective water cement ratio constant for all mixtures. Due to the high content of clay, particles of clay bricks and dust in fine fraction of RA from CDW treatment plant, the fraction $0-4 \mathrm{~mm}$ was removed. Because of using only the coarse fraction $4-16 \mathrm{~mm}$ of aggregate from recycling plant, the percentage of substitution was maximal $63 \%$ of the total amount of used aggregates, but it was $100 \%$ replacementof all coarse aggregate. Prepared concrete mixes are shown in Table 4. All the concrete mixes were designed for different replacements of natural aggregate (NA) by recycled aggregate (RA).

\subsection{Testing}

Density and water absorption capacity of aggregates were tested by pycnometer method according to EN 1097-6 [23]. Tested concrete specimens were subjected to 28-days wet curing. Tests of compressive strength were carried out on $150 \mathrm{~mm}$ cubes.

Mix proportion of concrete mixtures with laboratory prepared recycled aggregate $\left(\mathrm{kg} / \mathrm{m}^{3}\right)$

Table 3

\begin{tabular}{|c|c|c|c|c|c|c|c|c|c|}
\hline No. & $\begin{array}{c}\text { Replacement } \\
\text { percentage }\end{array}$ & Sand & $\begin{array}{c}\mathrm{NA} \\
4 / 8 \mathrm{~mm}\end{array}$ & $\begin{array}{c}\mathrm{NA} \\
8 / 16 \mathrm{~mm}\end{array}$ & $\begin{array}{c}\text { LRA } \\
0 / 16 \mathrm{~mm}\end{array}$ & $\mathrm{cem}$ & $\mathrm{w}$ & $\mathrm{w} / \mathrm{c}$ & $\mathrm{w} / \mathrm{c}_{\text {eff. }}$ \\
\hline NA & 0 & 774 & 346 & 641 & 0 & 345 & 180 & 0.52 & 0.52 \\
\hline LRA 1- 40 & 40 & 438 & 221 & 411 & 688 & 345 & 200 & 0.58 & 0.50 \\
\hline LRA 1- 50 & 50 & 356 & 188 & 347 & 868 & 345 & 200 & 0.58 & 0.48 \\
\hline LRA 1- 70 & 70 & 205 & 114 & 211 & 1234 & 345 & 200 & 0.58 & 0.43 \\
\hline LRA 2- 50 & 50 & 356 & 188 & 347 & 868 & 345 & 200 & 0.58 & 0.48 \\
\hline LRA 2- 70 & 70 & 205 & 114 & 211 & 1234 & 345 & 200 & 0.58 & 0.43 \\
\hline LRA 3- 40 & 40 & 438 & 221 & 411 & 688 & 345 & 200 & 0.58 & 0.50 \\
\hline LRA 3- 50 & 50 & 356 & 188 & 347 & 868 & 345 & 200 & 0.58 & 0.48 \\
\hline LRA 3- 70 & 70 & 205 & 114 & 211 & 1234 & 345 & 200 & 0.58 & 0.43 \\
\hline
\end{tabular}

Mix proportion of concrete mixtures with aggregate from recycling plant $\left(\mathrm{kg} / \mathrm{m}^{3}\right)$

\begin{tabular}{|c|c|c|c|c|c|c|c|c|c|}
\hline No. & $\begin{array}{c}\text { Replacement } \\
\text { percentage }\end{array}$ & Sand & NA 4/8 mm & NA $8 / 16 \mathrm{~mm}$ & $\begin{array}{c}\text { RA } \\
4 / 16 \mathrm{~mm}\end{array}$ & cem & w & w/c & w/ $\mathrm{c}_{\text {eff. }}$ \\
\hline NA & 0 & 767 & 458 & 726 & 0 & 320 & 160 & 0.50 & 0.50 \\
\hline RA 1-50 & 50 & 750 & 0 & 243 & 790 & 320 & 227 & 0.71 & 0.50 \\
\hline RA 1-63 & 63 & 748 & 0 & 0 & 991 & 320 & 235 & 0.73 & 0.50 \\
\hline RA 2-31 & 31 & 769 & 192 & 400 & 487 & 320 & 176 & 0.55 & 0.50 \\
\hline RA 2- 50 & 50 & 764 & 0 & 229 & 787 & 320 & 187 & 0.58 & 0.50 \\
\hline RA 2-63 & 63 & 766 & 0 & 0 & 967 & 320 & 191 & 0.60 & 0.50 \\
\hline
\end{tabular}


For flexural strength tests beams of dimensions $100 \times 100 \times 400 \mathrm{~mm}$ were used.

The compressive strength is the peak stress of the test specimens under uniaxial compression. It is the fundamental and important mechanical property of concrete which helps to sort concrete mixes to concrete strength classes. Five $150 \mathrm{~mm}$ cubes were prepared for each of tested concrete mixture.

The flexural strength test of the examined concrete was conducted on beams of size $100 \times 100 \times 400 \mathrm{~mm}^{3}$. Three concrete beams were casted for each concrete mix and cured for 28 days under usual laboratory conditions. The flexural strength was tested by four-point bending test.

\section{Results and discussion}

\subsection{Compressive strength}

The average test-results for concrete prepared from laboratory made recycled aggregate are shown in Fig. 2. This graph shows compressive strength of concrete with natural aggregate (NA), reference variant, and three types of recycled concrete prepared from laboratory made recycled aggregate (LRA1, LRA2 \& LRA3) with different replacement ratios. The graph shows correlation between replacement ratio and compressive strength. The compressive strength may depend on the composition of the original concrete mixture, but it would need more testing for relevant confirmation. LRA2 includes higher amount of cement than LRA1. Compressive strength of recycled concrete from LRA2 increases and recycled concrete from LRA1 decreases with replacement ratio of RA. But, on the other hand, recycled concrete from LRA3 decreases less than LRA1 regardless the original concrete mixture included the lowest amount of cement. Different results can indicate the problem with using fine fraction with high amount of milled cement. It is not possible to determine how much cement included in fine fraction exactly reacts with water. As a consequence, the amount of unreacted cement in LRA was able to cause higher compressive strength of mixtures included LRA than compressive strength of concrete with only NA.

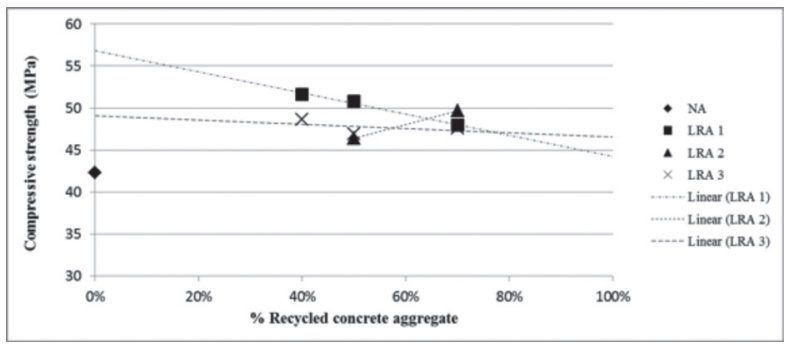

Fig. 2 Correlation between replacement ratio and compressive strength of recycled concrete with laboratory recycled aggregate
Furthermore, correlation between different replacement ratios of recycled aggregate was not proved in this part of investigation. Reference concrete shows lower compressive strength than recycled concretes, which may be due to content of cement in the fine fraction of recycled aggregates.

Correlation between replacement ratio and compressive strength of recycled concrete with recycled aggregate from recycling plant is shown in Fig. 3. This graph convincingly proved approximately linear dependence between mechanical properties of recycled concrete and amount of recycled aggregate in concrete mixture. The effective water cement ratio was kept constant for all mixtures, and there was no cement added to the recycled aggregate.

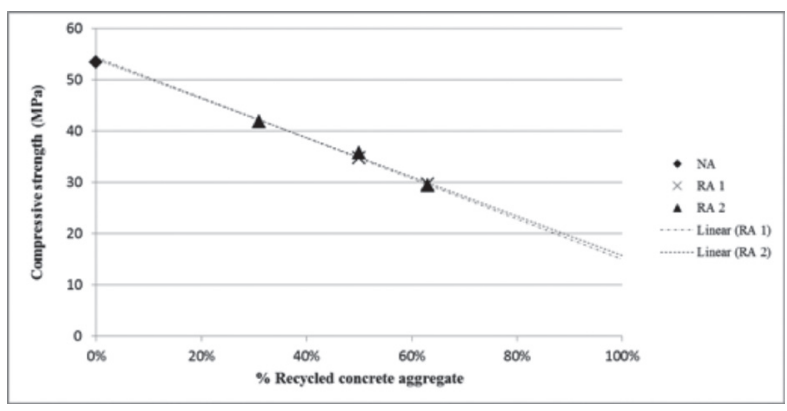

Fig. 3 Correlation between replacement ratio and compressive strength of recycled concrete with recycled aggregate from recycling plant

Generally, the compressive strength of recycled concrete decreased with the increased replacement ratio RA. The highest decline of compressive strength (more than $45 \%$ ) was found for concrete samples with $63 \%$ replacement ratio for both recycled aggregate samples from recycling plant (RA 1 and RA 2).

Different impact on mechanical properties of two types of recycled aggregate is caused by their different quality. Recycled aggregate from laboratory included only natural aggregate with adhered mortar. Howerer, recycled aggregate from recycling plant was contaminated with diverse substances, which negatively influenced mechanical properties of concrete.

\subsection{Flexural strength}

The relation between flexural strength of concrete and replacement ratio was the same as for compressive strength for both types of RA. With the increase of replacement ratio recycled aggregate (RA) the flexural strength of recycled concrete decreases. The highest decline of flexural strength was up to $13 \%$ for concrete samples with $63 \%$ replacement ratio for recycled aggregate (RA 2). 


\section{Conclusions}

The following conclusions can be drawn from this study. In the case of laboratory prepared RA the influence of properties of original concrete on the mechanical properties of recycled concrete was observed but due to a small number of tests it cannot be considered as a relevant confirmation. In the case of the use of RA from recycling plant, the increasing percentage of RA from recycling plant in recycled concrete have negative impact on the mechanical properties of final recycled concrete. The main degradation of properties was observed for compressive strength where $100 \%$ replacement of coarse fraction by recycled aggregate resulted in more than $45 \%$ decline of compressive strength. Important next step of the research is reliability of the reinforced recycled concrete with high percentage of RA concerning corrosion of steel reinforcement [24] and long term durability of recycled concrete in construction applications. Presented results confirm the decease of the mechanical properties of recycled concrete in relation to the quality of recycled aggregate. When the quality of recycled aggregate is known, the properties can meet the requirements of standards [6 and 25].

\section{Acknowledgments}

The research was funded by TA03010501 Optimized subtle frame for energy efficient buildings and SGS13/109/OHK1/2T/11 Additional constructions for light-weight concrete frame systems made from natural and recycled materials. All support is gratefully acknowledged.

\section{References}

[1] HAJEK, P.: Integrated Environmental Design and Optimisation of Concrete Slabs, in proc. Brisbane: CIA, 2003, Sv. Concrete in the $3^{\text {rd }}$ Millenium.

[2] THOMAS, C. et al. Evaluation of the Fatigue behavior of Recycled Aggregate Concrete. J. of Cleaner Production, 2013, 397-405.

[3] AKASH, R., KUMAR, N. J., SUDHIR, M.: Use of Aggregates from Recycled Construction. Resources, Conservation and Recycling, 2007, Sv. I, 50.

[4] BARDUDO, A., et al.: Influence of Water-reducing Admixtures on the Mechanical Performace of Recycled Concrete. J. of Cleaner Production, 2013, 59

[5] KHATIB, J. M.: Properties of Concrete Incorporating Fine Recycled Aggregate. Cement and Concrete Research, April 2005, 763769.

[6] EN 206-1 Concrete - Part 1: Specification, Performance, Production and Concrete, Brussels : European Union : CEN, 2000.

[7] AGRELA, F., et. al: Limiting Properties in the Characterisation of Mixed Recycled Aggregates. Construction and Building Materials, 2011, Sv. I, 25.

[8] HANSEN, T. C., NARUD, H.: Strength of Recycled Concrete Made from Crushed Concrete Coarse Aggregate. Concrete International, 1, January 1983, 79-83.

[9] DE BRITO, J., SAIKIA, N.: Recycled Aggregate in Concrete. London : Springer-Verlag, 2013.

[10] EVANGELISTA, L., DE BRITO, J.: Mechanical behaviour of Concrete Made with Fine Recycled Concrete Aggregates. Cement and Concrete Composites, May 2007, 397-401.

[11] XIAO, J., LI, J. A ZHANG, Ch.: Mechanical Properties of Recycled Aggregate Concrete under Uniaxial Loading. Cement and Concrete Research, 2005, 1187-1194.

[12] SAGOE-CRENTSIL, K. K., BROUWN, T., TAYLOR, A. H.: Performance of Concrete Made with Commercially Produced Coarse Recycled Concrete Aggregate. Cement and Concrete Research, 2001, 707-712.

[13] ETXEBERRIA, M., et al.: Influence of Amount of Recycled Coarse Aggregates and Production Process on Properties of Recycled Aggregate Concrete. Cement and Concrete Research, May 2007, 735-742.

[14] SANCHEZ DE JUAN, M.. GUTIERREZ, P. A.: Study on the Influence of Attached Mortar Content on the Properties of Recycled Concrete Aggregate. Construction and Building Materials, 23, 2009, 872-877.

[15] NIXON, P. J.: Recycled Concrete as an Aggregate for Concrete a Review. Material and Structures, Springer Netherlands, 1978, 371-378.

[16] EVANGELISTA, L., DE BRITO, J.: Durability Performance of Concrete Made with Fine Recycled Concrete Aggregates. Cement \& Concrete Composites 32, 2010, 9-14.

[17] BOEHME, Luc, et. al.: ValReCon20 - Valorization of Recycled Concrete Aggregates in Concrete C20/25 \& C25/30, Leuven : ACCO, 2012. 


\section{COMMNICOIIONS}

[18] LOPEZ-GAYARRE, F. et al.: Influence of Recycled Aggregate Quality and Proportioning Criteria on Recycled. Waste Management, 2009, 3022-3028.

[19] MARTINEZ-LAGE, I. et al.: Properties of Plain Concrete Made with Mixed Recycled Coarse Aggregate. Construction and Building Materials, December 2012, 171-176.

[20] BOEHME, L. et al.: Assessment of Water Reducing Admixture in Concrete with Recycled Aggregates, Prague : CESB13 - Central Europe towards Sustainable Building, 2013.

[21] TOPCU, I. B.: Physical and Mechanical Properties of Concretes Produced with Waste Concrete. Cement and Concrete Research, December 1997, 1817-1823.

[22] RAHAL, K.: Mechanical Properties of Concrete with Recycled Coarse Aggregate. Building and Environment, January $2007,407$. 415.

[23] EN 1097-6 Tests for Mechanical and Physical Properties of Aggregates - Part 6: Determination of Particle Density and Water Absorption, Brussels : European Union : CEN, 2000.

[24] KOTES, P., VICAN, J., SLAVIK, J.: Influence of Reinforcement Corrosion on Reliability of Existing Concrete Structures (in Slovak), Communications - Scientific Letters of the University of Zilina, vol. 3, No. 4, 2001, pp. 41-49, ISSN 1335-4205.

[25] CSN EN 12620 + A1. Aggregate for Concrete (in Czech). Praha : Cesky normalizacni institut, 2008. 